\title{
When Mental Walls Lead to Physical Walls: The US-Mexico Border Wall, Art, and Public Conversations about the Social Responsibility of Engineering
}

\author{
MADISON MAY MACIAS \\ ARIZONA STATE UNIVERSITY \\ PETER POHORILY ${ }^{2}$ \\ ARIZONA STATE UNIVERSITY \\ JORGE MORALES GUERRERO \\ ARIZONA STATE UNIVERSITY \\ DARSHAN M.A. KARWAT ${ }^{4}$ \\ ARIZONA STATE UNIVERSITY
}

\begin{abstract}
The fact that engineering is involved in highly political issues-from climate change caused by fossil fuel extraction to how we understand truth itself because of deepfakes-makes it imperative that we find new ways to highlight the crucial role that engineers and engineering play in shaping society, and new ways to hold engineers and engineering accountable. We have designed, built, and installed an interactive art installation called When Mental Walls Lead to Physical Walls to generate public conversation about the social responsibility of engineers and engineering, using the US-Mexico border wall as a case study. We find that the politically charged nature of the topic might make it difficult for attendees to speak directly to ideas of social responsibility. At the same time, the installation provides opportunities for attendees to question, critique, and reflect on the effectiveness and impacts of the design of the border wall and the motivations engineers might have in working on this project. With proper planning and execution, the installation can be used as a research tool to understand how diverse audiences-from engineering students to those who may not have any experience in engineering-understand the role of engineering in society.
\end{abstract}

\section{Keywords}

engineering; border wall; US-Mexico border wall; social responsibility; infrastructure; immigration

\footnotetext{
${ }^{1}$ Madison May Macias, Email: mmmacias@asu.edu 2 Peter Pohorily, Email: ppohoril@asu.edu

3 Jorge Morales Guerrero, Email: jmoral31@asu.edu

· Darshan M.A. Karwat, Email: darshan.karwat@asu.edu

Copyright (C) 2020 (Madison May Macias, Peter Pohrily, Jorge Morales Guerrero, Darshan M.A. Karwat). Licensed under the Creative Commons Attribution Non-commercial No Derivatives (by-nc-nd). Available at estsjournal.org.
} 


\section{Introduction and Motivation}

Whether it is deepfakes, climate change, or extended wars, technology—and by extension the work of engineers-is implicated in many of the important social, ecological, and political issues societies across the world face (IPCC 2015; Villasenor 2019; D. M. A. Karwat 2019). Addressing social challenges is thus implicitly and explicitly about critically examining and reimagining the kind of engineering that engineers do. The case of immigration between the US and its southern neighbor is no different. President Donald Trump has made the building of new border barriers and walls between the US and Mexico a defining issue in the immigration debate for his presidency (Rodgers and Bailey 2019; Scott 2015, 2019; Bender 2019; Bump 2016), thereby bringing into the issue's fold the work of engineers. In 2017, US Customs and Border Protection issued a solicitation that issued the first set of technical specifications that engineering firms had to meet in their proposals. More than 500 engineering companies expressed interest with more than 200 applying (Miller 2017). Engineers and firms have not shied away from injecting themselves from the border wall debate, by either proposing to build it or by proposing alternative engineering interventions. The spectrum of engineering interventions has ranged from creating barriers (Miroff 2019) to hyperloops (Born to Engineer 2017) and industrial zones (Kullman 2019). Between the beginning of the Trump presidency and September 2019, "approximately 64 miles of new border-wall system" has replaced dilapidated parts of existing border walls (Rizzo 2019).

At the same time, companies working on the border wall have faced backlash for their work on it (Adler 2017; Berrien 2018; Crabtree 2018; Orenstein 2017; Brinklow 2017; G. 2018), thus raising questions about the social responsibility of engineering companies working on projects like border walls, about the role of engineering in society, and the politics of engineering. There has been significant research in the public perceptions of technology, including technologies like geoengineering (Kaplan et al. 2019), nanotechnology (Besley 2010), and artificial intelligence (Fast and Horvitz 2017), among many others. This research has investigated public questions, concerns, and recommendations regarding whether and how technologies should be developed. Much less has been written about how the public thinks about the social responsibility of engineers, the ones designing and building these technologies, themselves. While many people may hold a favorable opinion of engineers, research has shown that those without technical training may not fully understand what engineers do and what the occupation of engineering consists of (engineerscanada 2017). For example, a study performed in the UK in 2007 among 1,000 diverse respondents showed a "limited initial awareness and understanding of engineering and engineers" (Marshall, McClymont, and Joyce 2007). An exhaustive search for and review of studies relating to the perception of engineers and engineering proved that this study remains one of the only studies on the public perceptions of engineering and engineers, let alone of their social responsibility practices, or lack thereof.

If engineering - the actual process of it, the nitty-gritty, day-to-day decision-making, design, and analysis--happens out of the public eye and with little public understanding, how might we get people thinking about the role of the profession and its social responsibility in society, especially given the crucial role that engineering plays in most facets of our lives? Given an opportunity to engage with the public in the Phoenix/Tempe area on issues of society and 
technology, we wanted to understand how the public views the social responsibility of engineers and engineering, as seen through the case of the US-Mexico border wall. Drawing inspiration from how artists and researchers have used art to raise public awareness and teach people about science, technology, engineering, and mathematics (Guyotte et al. 2014; Barniskis 2014; Clarke 2019), we designed When Mental Walls Lead to Physical Walls, a public art experience, to provide us this understanding and to generate new conversations about the public perceptions of engineering and technology. Below, we describe our design of this installation, the data we gathered, and our analysis and reflections on them all.

\section{Our Design to Generate a Public Conversation}

The name of our installation, When Mental Walls Lead to Physical Walls, is a nod to how engineers separate the political from the technical aspects and implications of their work (Felt et al. 2017; Hecht and Callon 2009; Noble 1978). Engineers working on the US-Mexico border wall are no different. Below are three quotes from engineers and managers whose companies submitted bids in 2017 to help continue expanding the US-Mexico border wall:

- “We're not into politics. We're not left or right. We're a construction company, and that's how we survive. ... We don't see it as politics. We just see it as work," Jorge Diaz, Manager of De la Fuente Construction Inc. in California, told the Guardian (Wong 2017).

- 'We're focused on the work, we're not a political body, left or right or what have you. We go after the job and provide high-paying jobs for our workforce and great opportunities for our company," Ralph Hicks, vice president of governmental affairs for R.E. Staite Engineering in California, said to KPBS (Guerrero 2017).

- $\quad$ "There could be a political backlash, but we are in business to make money and put people to work and provide a good service, whether it's a wall or substation or airport or prison. We don't want to approach it from a political standpoint, only from a business standpoint," George Ishee, national sales manager for Cast Lighting, based in Hawthorne, New Jersey, told NorthJersey (Adely and Alvarado 2017).

As suggested by the quote from George Ishee above, this separation-which one might imagine being created by engineers constructing a mental wall in their minds-indeed leads to the creation of a physical wall in the case of the US-Mexico border. To emphasize this point, we articulated experience goals and engineering design criteria. Our experience goals were to convey to attendees the complexity and history, and a sense of scale:

- Complexity and history: We wanted to convey to attendees an understanding of how engineering is driven by business opportunities; that political visions of building a border wall must be converted into technical specifications to guide engineering work; that even for politically charged technologies, the engineering work to design the 
technologies can be routine and almost mundane; and that the US is not the only nation in the world that is building or has built border barriers and walls (they are quite common).

- Scale: An assumption we had was that most people-even those living in a border state like Arizona-have not seen a border wall. Thus, we wanted attendees to get a feeling of how big, tall, sturdy, and imposing border walls can be. We wanted people to look up-like one does when looking at a tall building or at a rocket on its way into spaceand feel the presence of something big, imposing, and that looked like an actual border wall.

Our engineering design criteria were that the installation had to be safe (including to interact with) given the presence of thousands of possible patrons; it also had to be modular because we wanted to be able to quickly assemble and disassemble the entire installation within one hour, and because we wanted it to be easily stored for future use. The fact that we didn't have the ability to lay a foundation limited the height of the wall to $12 \mathrm{feet}$, which is still tall enough to make one's neck turn up if they were reading something at the top while standing at its base. Not having a foundation also meant that the structure needed to be designed to be self-standing and stabilizing. A Z-shape where the angles are 90 degrees did the trick. Using standard construction techniques, we built the wall using $2 \times 4 \mathrm{~s}, 4 \times 4 \mathrm{~s}, 4 \times 6 \mathrm{~s}$, steel studs, Masonite, and self-tapping screws. The sturdiness of the design also allowed people to touch the wall and put sticky notes with their thoughts on it. We painted the wall a light gray, covered it with decals (see below), and then finished it with coats of clear spray paint.
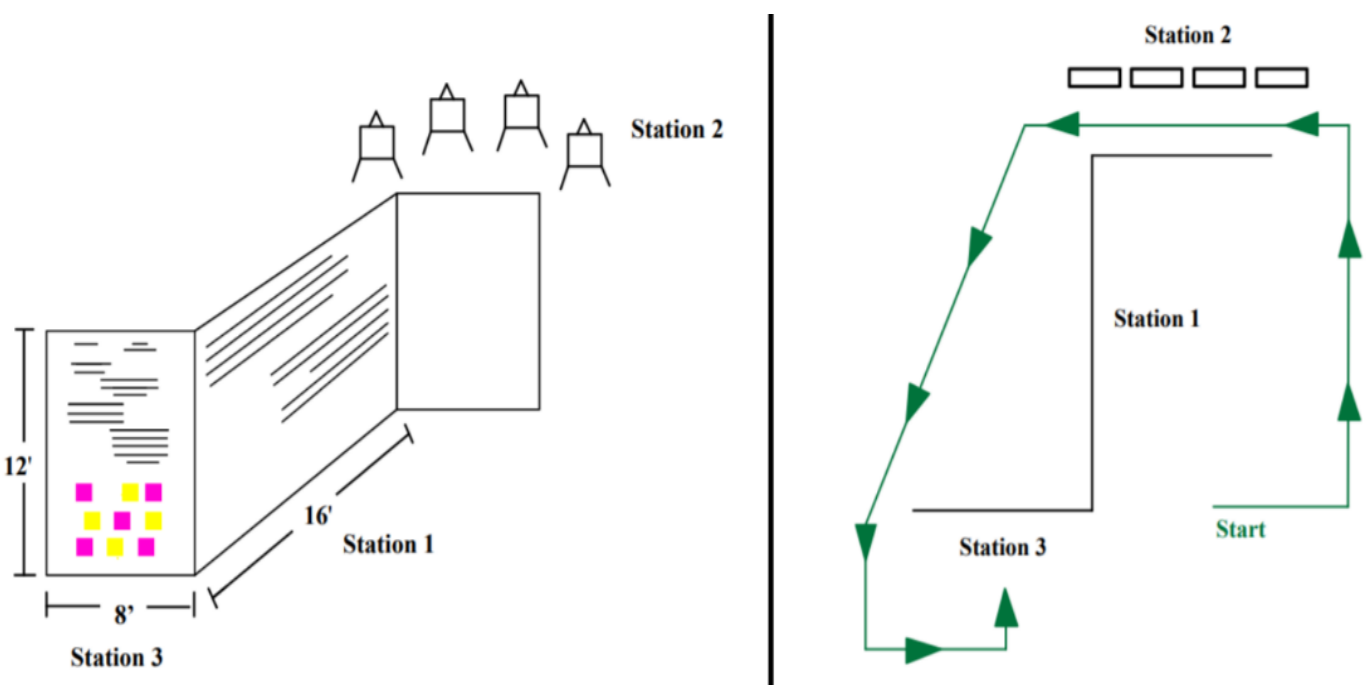

Figure 1: The left panel of the figure depicts an isometric view and dimensions of the installation, and the right panel provides a bird's eye view and patron pathing of the installation. Station 1: "When Mental Walls Lead to Physical Walls," Station 2: "Museum of Walls" and Station 3: "Wall of Thoughts." 
Based on these goals and criteria, we designed the experience to consist of three "stations," which can be seen in Figures 1-6. Each station, described below, provides a different insight into the role of engineering in designing and building the US-Mexico border wall, and all stations, with the exception of the engineer's notebook, are displayed in both English and Spanish.

\section{Stations}

Station 1 is called When Mental Walls Lead to Physical Walls, the name of the entire installation and experience. On one side of the $12^{\prime}$ tall and $16^{\prime}$ wide wall we displayed using decals the quote by George Ishee of Cast Lighting (repeated below), a company that in 2017 expressed its interest in expanding the US-Mexico border wall (Adely and Alvarado 2017):

There could be a political backlash, but we are in business to make money and put people to work and provide a good service, whether it's a wall or substation or airport or prison. We don't want to approach it from a political standpoint, only from a business standpoint.

This quote is an example of how engineers separate out the "political" from the "technical" aspects of engineering work and is just one of many similar quotes from engineers and companies that expressed their interest in border wall work since 2017. The other side of the wall-also created using decals-resembles the inside of a notebook used by an engineer working on the USMexico border wall, complete with sketches, thoughts, ideas, and the mundane aspects of designing a wall. The wall itself represents the wall that engineers build in their heads to separate the technical work they do and the political impacts of the work they do.

Station 2 is called the Museum of Walls, and it is a quick but multi-perspective take on border barriers around the world, the history of the US-Mexico border, the technical specifications of the US-Mexico border wall as described in US Customs and Border Patrol solicitations (Doubek 2017), and eight designs that were chosen in 2018 to be prototyped (Koscak 2017). This station emphasizes how political signals like "Build the wall!" (Johnson 2016) get converted into technical specifications that allow engineers to work on technological projects.

Station 3, the final station, is called the Wall of Thoughts and provides attendees the opportunity to share their thoughts (using sticky notes) on engineers, engineering, and social responsibility guided by two questions: "What is the role of engineers and engineering in society?" (Question 1) and "What would you like to ask or say to an engineer or company working on the US-Mexico border wall?" (Question 2). We intentionally left the questions open-ended and broad to understand the range of thoughts, emotions, and reactions in response to the work engineers are doing in designing and building the border wall, and to understand the associations people might make between the engineering of the border wall and the engineering of other technological systems in ways that highlight the social responsibility of engineers and engineering. 


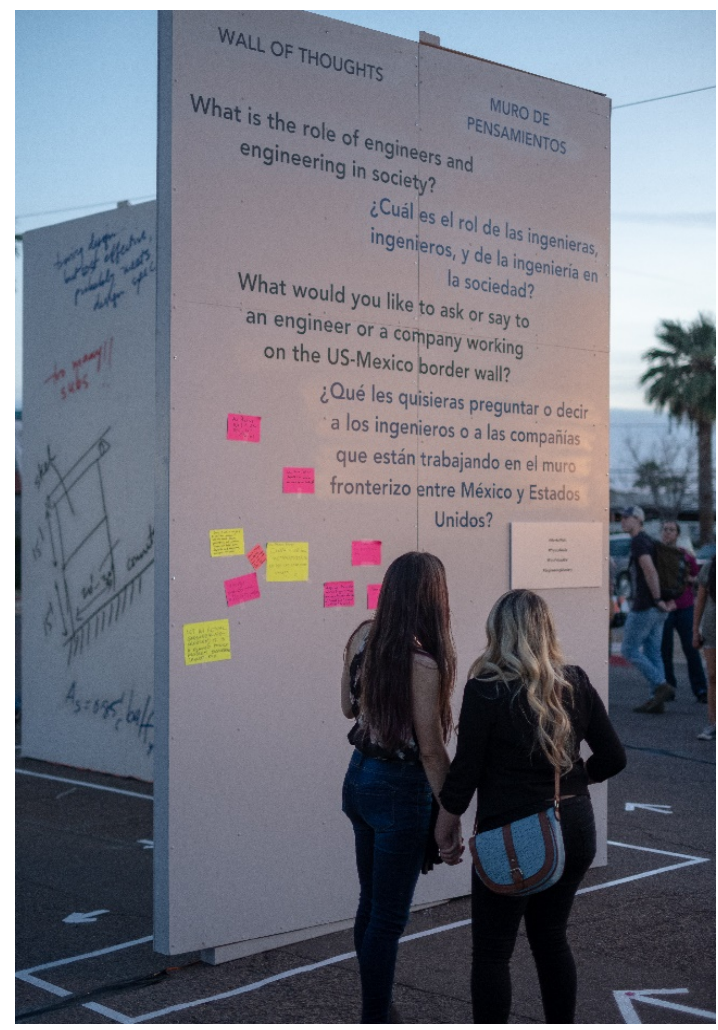

Figure 2: Two attendees in front of Station 3: "Wall of Thoughts."

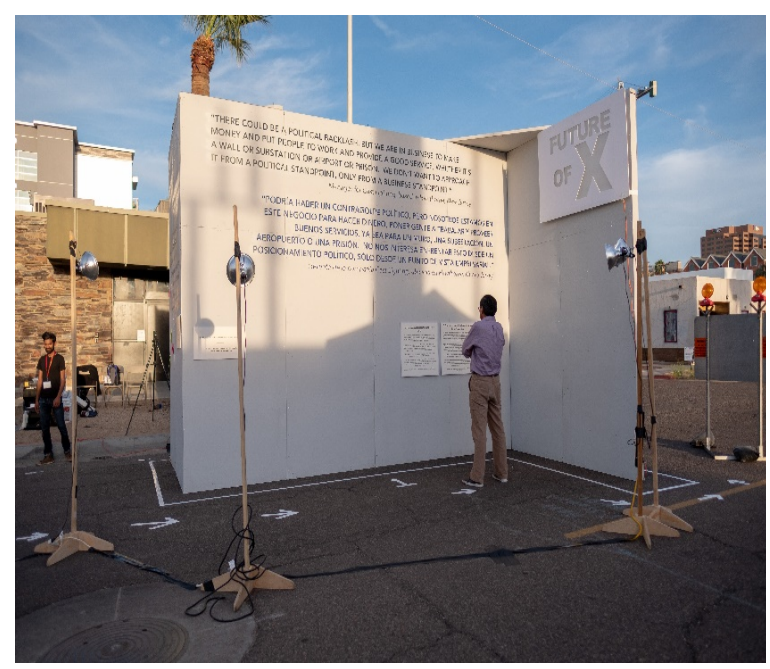

Figure 3: Station 1: “When Mental Walls Lead to Physical Walls."

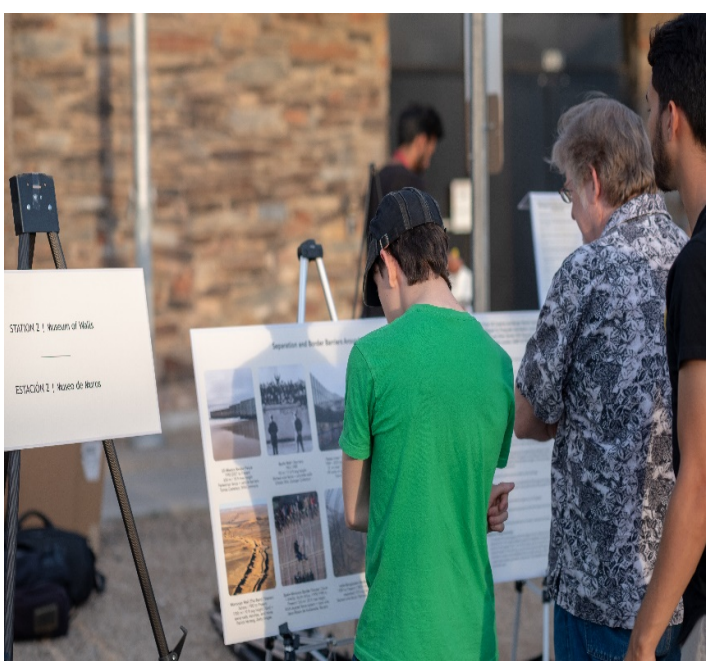

Figure 4: Attendees in front of Station 2: "Museum of Walls."

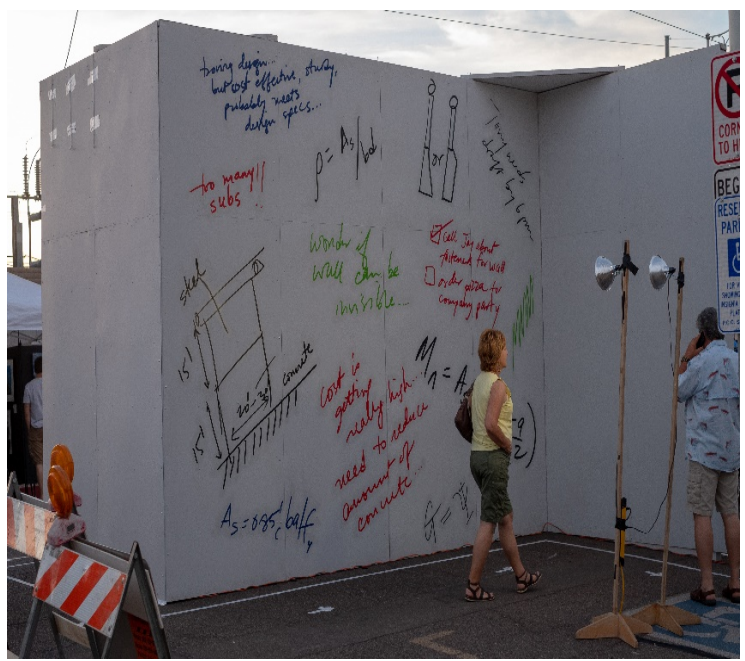

Figure 5: "The Engineer's Notebook" appearing on the back side of Station 1.

Copyright ( 2020 (Madison May Macias, Peter Pohrily, Jorge Morales Guerrero, Darshan M.A. Karwat). Licensed under the Creative Commons Attribution Non-commercial No Derivatives (by-nc-nd). Available at estsjournal.org. 
The experience directs visitors around the whole structure in a counter-clockwise path. Public engagement was central to the design of the experience, and we allow guests to interact with the Wall of Thoughts by anonymously writing responses on sticky notes and filling the front flanking end of the installation. While we initially did not think of the experience as a research tool or site, conducting research with a mobile art installation has, in our estimation as discussed below, allowed us to engage with audiences not generally spoken to about the social responsibility of engineers. Aligning with the ideologies of Cole and McIntyre's Installation Art-AsResearch (McIntyre 2008), Richard Jackson explains, "it is designed to take ideas from academic research, present them to diverse audiences, and through interaction with attendees, engage their ideas and reflections; it does not take a Ph.D. to engage with it." We have also completed a design packet (available at www.reengineered.org/wmwltpw) for those who want to build this installation themselves (Macias 2019). (Please reach out to us if you are interested!)

\section{Data Gathering and Analysis}

We installed When Mental Walls Lead to Physical Walls twice. First, we installed it at the Downtown Phoenix First Friday in April 2018. Organized and managed by Artlink Phoenix, a 501(c)(3) nonprofit organization that organizes First Fridays (Artlink, Inc. 2019), “First Friday features selfguided tours of downtown Phoenix art galleries, studios, and creative spaces and is 'dedicated to bringing together artists, the public, and businesses for a greater understanding, appreciation, and promotion of the arts and the development of a strong and vital downtown Phoenix arts community'" (Hedding 2019). While we have no estimate for the number of people who walked by the experience, past estimates for the total number of attendees at First Friday have ranged between 15,000 to 45,000 people, with the range taking into account the hot Phoenix summer months (Otto 2018). The second time we installed When Mental Walls Lead to Physical Walls was for Emerge in March 2019, which is a yearly "festival of art, science, and technology devoted to creative imagination and experiences of tomorrow" organized at Arizona State University on the Tempe campus; there were approximately 400 attendees at Emerge. The volunteers who supervised the art installment were prepared beforehand with a shortlist of questions to engage with participants if approached. While we recognize the act of putting up such an installation is a political act in itself, volunteers staffing the installation only discussed the details on the installation and offered no direct personal opinions on the subject matter engaged by the installation. Instead, when asked questions, volunteers directed guests with questions back to contemplating and answering the questions posed on the Wall of Thoughts.

At each event, we gave attendees small and large sticky notes and sharpie markers so that patrons could share their thoughts-especially on the social responsibility of engineers-at the Wall of Thoughts (Station 3). We chose to use sticky notes because they are inexpensive, easy to use, and allow respondents to remain anonymous. We also recorded five interviews at First Friday to ask attendees directly about their responses to the questions on the Wall of Thoughts.

Between the two installations, we gathered 255 sticky note responses, with 223 being from First Friday and 32 being from Emerge. Each individual response was transcribed into a 
spreadsheet as accurately as possible, including by keeping profanity, unrelated comments, capitalizations, abbreviations, symbols, and grammatical errors. We translated responses that were in foreign languages (primarily Spanish) and ensured translational accuracy. Figure 7 shows examples of responses posted on the Wall of Thoughts. As we discuss below, not all of the responses we received were direct responses to the two questions on the Wall of Thoughts. The following images depict some of the responses gathered from First Friday:

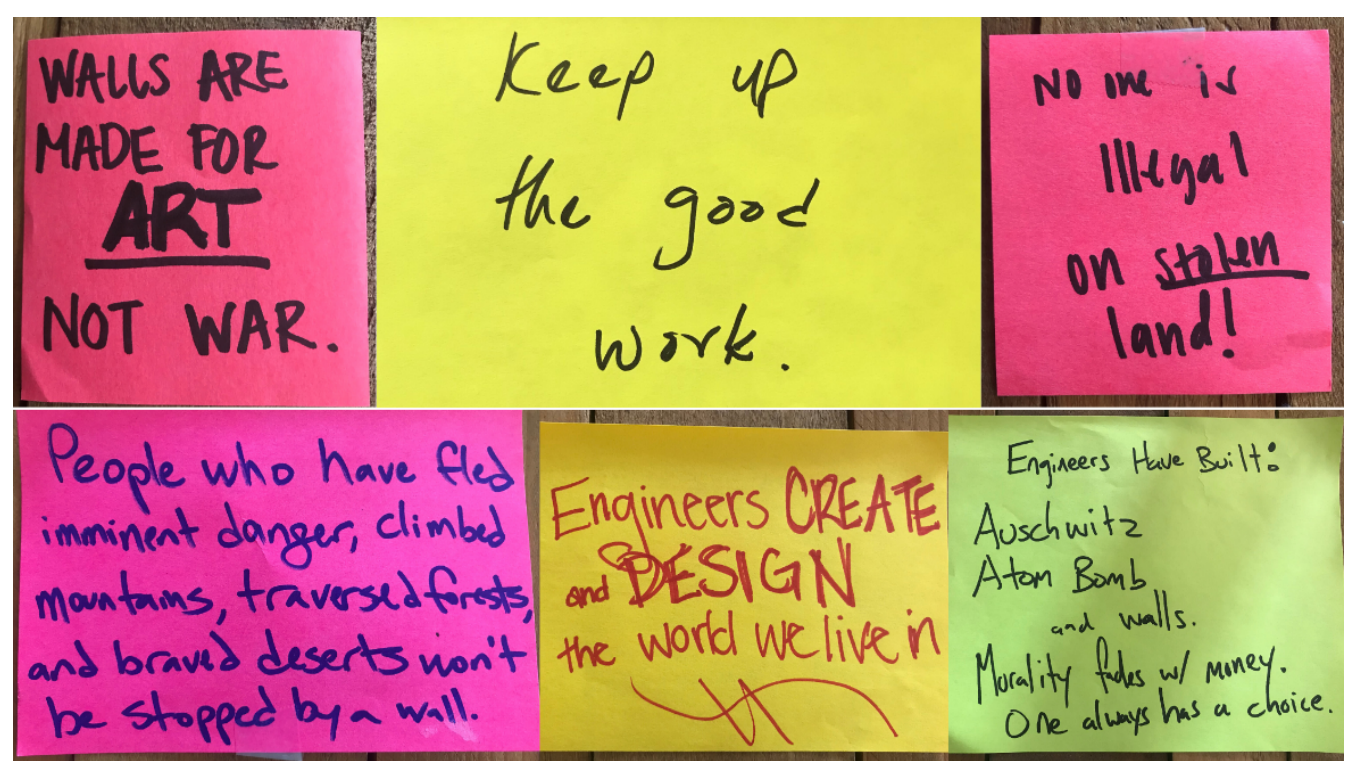

Figure 6: Six responses gathered at the First Friday showing.

We inductively coded the 255 responses, generating 16 unique codes, which we divided into 11 "content codes" and five "tracking codes." Content codes are those codes that describe the topic area of the response. The content codes that emerged were immigration; environmental concerns; inability to fulfill purpose; denouncement of purpose; reallocation of skills and resources; monetary motivations and allocations; ethics, empathy, and values; questions to engineers; questions on design and execution; political groups and figures; and unrelated. Tracking codes are those codes that allowed us to track the nature of the response. The tracking codes that emerged were responses to Question 1; responses to Question 2; free response; profanity; and love. We assigned all responses a minimum of one content code and one tracking code each. At a higher level, these 16 codes were organized into themes: politics and policy; design effectiveness and impacts; motivations, ethics, and purpose; expression; response; and miscellaneous. 


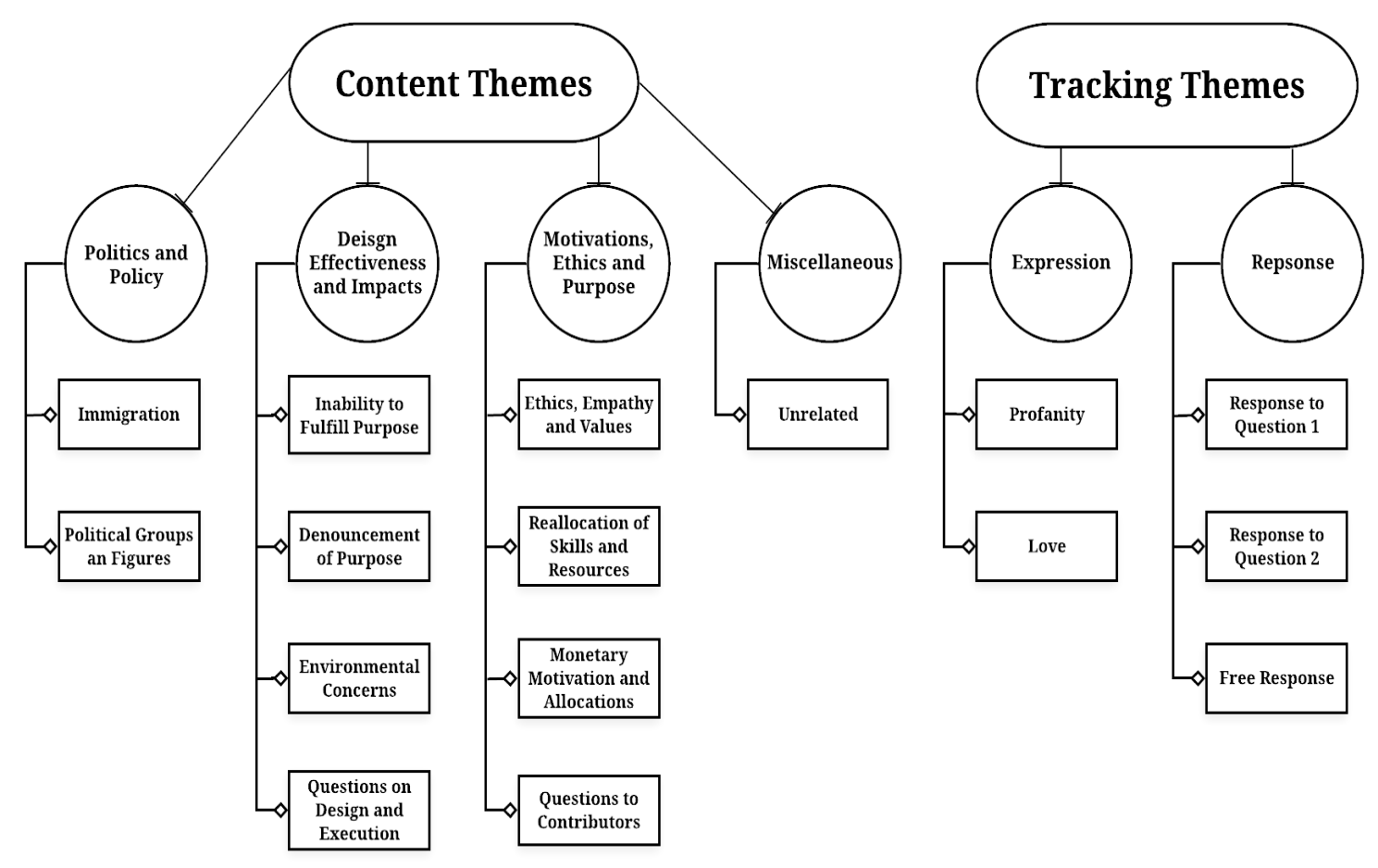

Figure 7: Codes that emerged through our analysis.

Below is a description of the themes (bold italics) and codes (bold bullet points). We give one example for each of the codes below:

\section{Content Theme 1: Politics and Policy}

This theme refers to codes relating to policy and political figures and groups.

- Immigration: Responses that offer direct and indirect commentary regarding immigration and / or immigration policy and all associated impacts. Some of the responses include content that praises the border wall and/or immigration control and comments that talk about direct personal impacts experienced due to immigration control. Example: "People who have fled imminent danger, climbed mountains, traversed forests, and braved deserts won't be stopped by a wall."

- Political Groups and Figures: Responses that mention a political figure or political group, including celebrities that are mentioned in the context of politics. Example: "Build the wall Trump $2020 ! "$ 


\section{Content Theme 2: Design Effectiveness and Impacts}

This theme refers codes that discuss or question the need, effectiveness, and rippling effects regarding the construction and design of the border wall on society, politics, and the environment.

- Inability to Fulfill Purpose: Responses that suggest the newly proposed border wall won't serve the intended purpose of providing better illegal immigration control. Example: "What if the wall is not sufficient because there is underground passage so what's the point?"

- Denouncement of Purpose: Responses that suggest that the border wall won't serve any purpose at all and/or explicitly denounce the wall with no other suggested courses of action. Example: "¿Qué hago aquí? No sé a qué lado ir. Mi amor y mi hija están del otro lado y quiero estar con ellos. Este muro no tiene ningún propósito, es inhumano" (What do I do here, I do not know which side to go. My love and my daughter are on the other side and I want to be with them. This wall has no purpose, it is inhumane.)

- $\quad$ Environmental Concerns: Responses that questioned or rebuked the environmental and ecological impact of the border wall. Example: "How would the wall affect migration patterns and ecosystems of animals?"

- Questions on Design and Execution: General inquiries about the design, functionality, and construction of the border wall. Example: "How will these work crews of men be fed and policed? Look what happened at the fracking boom in N. Dakota."

\section{Content Theme 3: Motivations, Ethics, and Purpose}

This theme refers to codes that discuss the purpose, motivations, and intentions of all contributors to the border wall, which we define as all engineers, companies, and working professionals actively making and overseeing decisions for the border wall in general.

- $\quad$ Ethics, Empathy, and Values: Responses that question the morality and ethics, or lack thereof, of the concept of the border wall and the people working on it. Example: "Never mind the politics, think about the morality of what you're being asked to do. You have the FINAL say in your actions. Stand up and say NO!! (My family was separated by the Berlin Wall)."

- Reallocation of Skills and Resources: Responses that suggest that the skills and resources being funneled into the new proposed US-Mexico border wall, engineering or otherwise, should be used differently or for a different cause. Example: "Please find another job."

- Monetary Motivations and Allocations: Responses that rebuke the perceived greed, monetary motivations, and / or use of money being directed towards the border wall and the people working on it. Example: "There are only a few ways in which the money would go to a poorer cause. F the wall."

- Questions to Contributors: Responses that contained general inquiries posed to the engineers and companies working on the border wall. Example: "Do we train Engineers to consider the wider consequences of design choices?" 


\section{Content Theme 4: Miscellaneous}

This theme code refers to topics not strongly related to the questions posed or the surrounding politics.

- Unrelated: Responses that expressed opinions completely unrelated to the surrounding politics and/or context of the project, which cannot be classified into existing codes. Example: "RAWR XD."

\section{Tracking Theme 1: Expression}

These are codes that contain heavily expressive language and content.

- Love: Responses that promote or mention the word "love." Example: "BRING US TOGETHER!! \#lovewins"

- Profanity: Responses containing profanity or explicit language. Example: "Fuck the wall."

\section{Tracking Theme 2: Response}

These are codes to track what question the response does or does not answer.

- Response to Question 1: Responses addressing the first question on the Wall of Thoughts, which reads, "What is the role of engineers and engineering in society?" Example: "The role of an engineer is to use their technical expertise to solve real world problems. Their solutions should benefit society, making life better and easier. A wall between the US \& Mexico does not solve America's problem or make life better or easier. —an actual engineer."

- Response to Question 2: Responses explicitly phrased in a way that directly address an engineer or company working on the project and could be considered as answering the second question posed on the Wall of Thoughts, which reads "What would you like to ask or say to an engineer or company working on the US-Mexico border wall?" Example: "Are there better projects you could be working on instead?"

- $\quad$ Free Response: Responses that answered neither of the questions posed on the Wall of Thoughts. Example: "The only wall I acknowledge is Pink Floyd's THE WALL."

The codes "inability to fulfill purpose" and "denouncement of purpose" originally appeared as one combined code. Through greater analysis, we decided to further subcategorize them based on the differentiation of comments that say the proposed border wall will not serve the intended purpose and comments that simply suggest it has no purpose due to the patron's beliefs on immigration. Codes we marked as "Reallocation of Skills and Resources" were not marked as "Inability to Fulfill Purpose" or "Denouncement of Purpose" because these latter two codes were used only when no other direct action is suggested when denouncing the wall, whereas codes marked as "Reallocation of Skills and Resources" also either criticize or denounce the wall implicitly, but explicitly suggest that efforts should be funneled elsewhere. When assigning the codes of "Response to Question 1" and "Response to Question 2," we interpreted each response as 
broadly as possible to see whether it answered either question. For codes marked as "Response to Question 2," we considered if the comment could be addressing engineers or the companies involved in the project about the design or the construction of the wall or the politics surrounding it. If it didn't and was something that could be universally addressed to anyone, then we considered it to not fall under the code.

Table 1 shows the statistics of the codes we found from the 255 responses we gathered across the two installations. The percentages for both the Content codes and Tracking codes add up to greater than $100 \%$ because we assigned a significant fraction of the responses multiple codes; in other words, many responses hit on more than one issue. Given this multiple coding, the total sum of the content codes does not equal the total sum of the tracking codes. A few highlights from the responses: At both events, "Immigration" was a dominant topic in the responses, as one might expect, along with responses that denounced the purpose of the wall, or that suggested the wall wouldn't fulfill its intended purpose. Importantly, it is clear that respondents felt the most compelled to answer the second question on the Wall of Thoughts: "What would you like to ask or say to an engineer or company working on the US-Mexico border wall?" $83 \%$ of all responses addressed this question, and only $3.1 \%$ of them answered the broader first question on the Wall of Thoughts: "What is the role of engineers and engineering in society?" There are a couple of possible reasons for this, as we describe below.

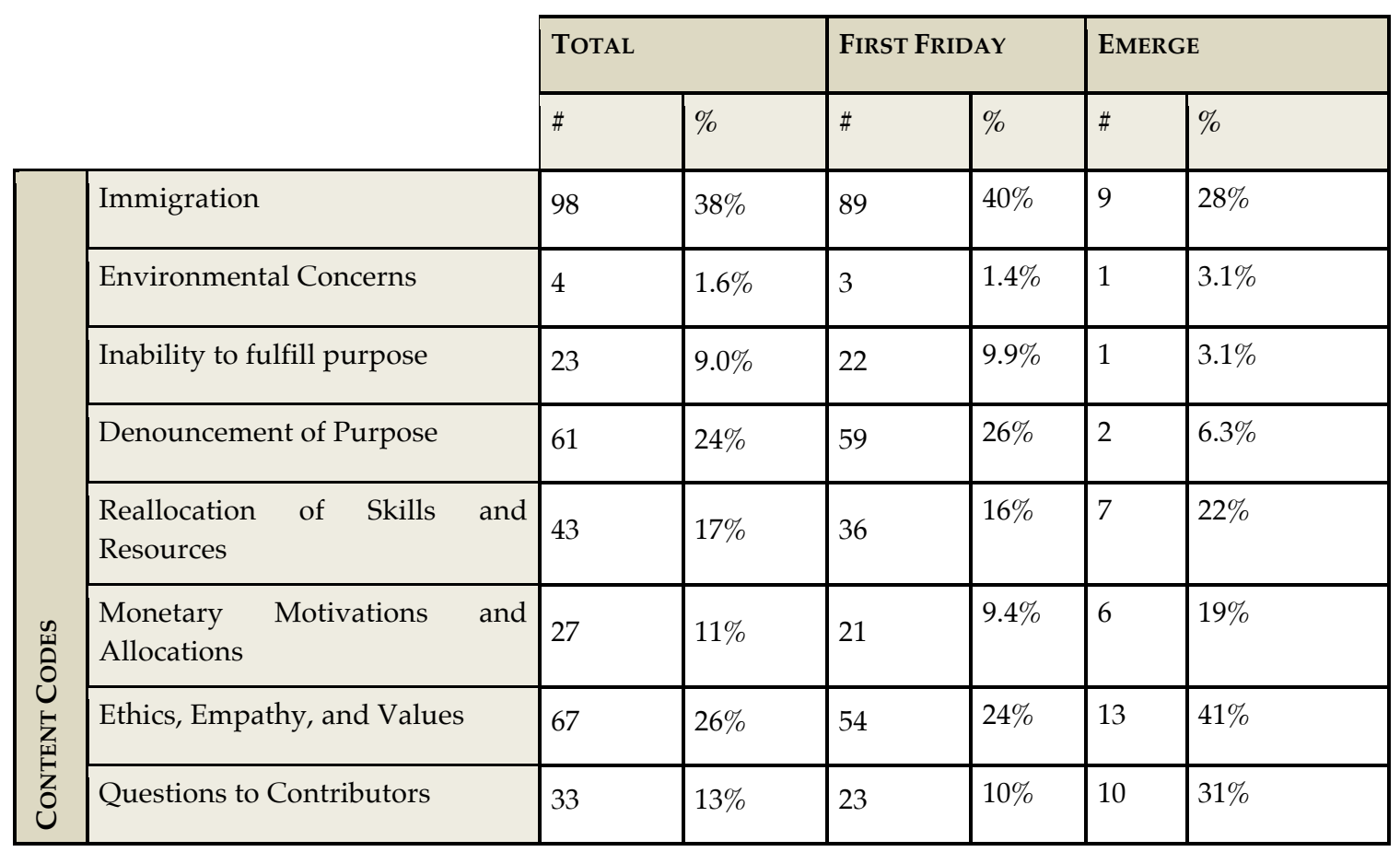




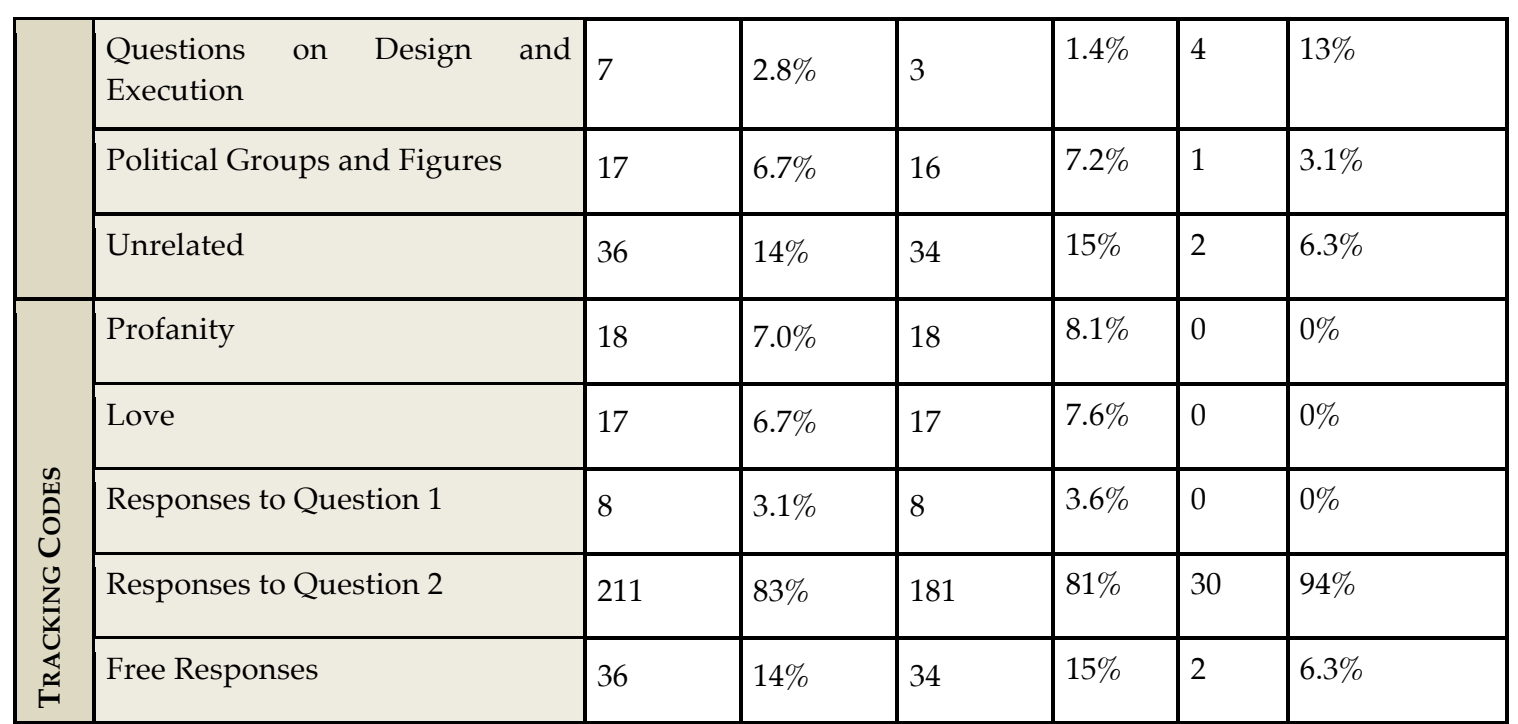

Table 1: Counts and percentages of each code we found in the responses we gathered between two installments of When Mental Walls Lead to Physical Walls.

\section{Discussion}

Our intent with this installation was to generate and understand public perceptions about the social responsibility of engineers and engineering, and our coding structure provides a high-level view of what people are compelled to talk about regarding the installation, and the politics surrounding the engineering of the border wall. Codes under the content themes "Design Effectiveness and Impacts" and "Motivations, Ethics, and Purpose" speak implicitly or directly to the engineering aspects of the wall, and a significant number of responses fell under these themes. Broadly, the diversity of the codes shows the multifaceted nature of attendee's thoughts on the issue of the border wall. The fact that a large majority of the attendees did not directly answer Question 1 on the Wall of Thoughts may have to do with the emotionally and politically charged nature of the debate around the border wall, hindering responses to questions not directly related to people's almost intuitive responses to border wall issues. It is easy to imagine people having more wellformed responses to Question 2 because the installation provides a space for attendees to vent their existing support for or frustrations with the border wall debate-given the pervasiveness of the border wall debate-regardless of what side of the issue they fall on; a vast majority of respondents provided feedback, critique, or praise to the engineers and companies working on border wall. This observation may be explained by the thoughts of Paula Ioanide, who writes in The Emotional Politics of Racism: "Any time our emotional structures experience danger, fear, or anxiety-affects that are all too common in the discussions of systematic oppression-our capacity to integrate knowledge and participate in communicative acts also tends to diminish" (Ioanide 2015). The imposing nature of the installation-designed to be so intentionally to give people a sense of what it is like to be next to a large wall--may be evoking sometimes-polarizing emotional responses that 
make respondents eager to sound off at contributors to the proposed border wall, or provide free responses. It may also be the case that many attendees may not feel well-versed enough about the forces that shape engineering to discuss its role in society.

Viewed differently, however, given the significant number of responses that relate to the ability of the wall to serve its intended function, and the role of the border wall in the larger debate about immigration, we can make inferences about what attendees feel about the social responsibility of engineers, or ways in which they would like to push engineers to consider their social responsibility and the values embedded in their work. For example, the response "How would the wall affect migration patterns and ecosystems of animals?" under the code "Environmental Concerns" suggests that engineers should consider the impact of the border wall on wildlife, thus implying that engineers' realm of consideration in technological design ought to extend to wildlife. The response "When you have more than you need, build a longer table, not a higher wall," coded under "Immigration," "Reallocation of Skills and Resources," and "Ethics, Empathy, and Values," suggests that engineers should explicitly support those who lack access to resources. Further, given the significant number of responses coded under "Ethics, Empathy, and Values" not simultaneously coded as a direct response to Question 2, we infer that many attendees feel that it is important for engineers to think about the issue of the border wall more holistically than to simply value the business opportunity of working on the border wall.

The dearth of direct responses to Question 1 may also be due in part to our data collection methods. As mentioned earlier, we also conducted five interviews (SFIS ASU 2018; D. M. A. Karwat 2018) with random attendees in which we asked them the questions on the Wall of Thoughts, and in that case, we did receive in-depth responses to Question 1. As is evident from two quotes from the interviews, as seen below, attendees were much more articulate about the social responsibility of engineers, and the difficulties some may face in making decisions that align with their values. For example, one First Friday attendee said:

For the engineers, I would say, "Do a good job, but be questioned whether actually, this is particular work you would want to take." And for the companies, and in my field, there's some business I don't take because it's not anything I want to be involved in. The guys who own those companies can decide whether or not they want to be involved. Scientists, certainly, as moral individuals, may choose to opt-in or out of a project, but when we think of probably the greatest moral conundrum in the modern era, it is when Oppenheimer continued to build the atomic bomb, knowing exactly what it was going to be used for.

A second attendee said:

I'm working in a powerhouse, and that's a coal fire burning powerhouse, and that's putting pollution in the air, but at the same time, that's putting money in my pocket and having my kids and having my way of life, that living, so it's a double-edged sword. I've been a welder; I worked construction ever since I was in high school; what else can I do? 
We thus identify a tradeoff in our installation if used for research: while the free-to-roamaround and easy-to-engage-with design of our installation might engage diverse audiences and large numbers of attendees, we may not get the depth of engagement we seek to understand public perceptions regarding broad questions about the social responsibility of engineers and engineering. Further, as seen through some of the responses we received, sticky notes can provide attendees the opportunity to "sound off," so to speak, rather than provide insightful comments or responses on the topics of interest. This is similar to, as a reviewer for this paper suggested, an online comment section, where comments can be anonymous with respondents not needing to take responsibility for the effects of their comments. Thus, trade-offs emerge for researchers and public experience designers in selecting between a public input mechanism that is streamlined and quick, that allows for many people to engage, that provides rich responses, or that requires minimal person power.

Even if we were to refine the questions on the Wall of Thoughts to be less open-ended and broad, there is no guarantee, given limited resources, that we would get a high volume of responses answering those questions. At the same time, we are encouraged by the fact that more than $85 \%$ of the responses we received did, in some way, shape, or form, address or relate to engineers and/or engineering considerations. If we did want to conduct larger numbers of interviews, we could set up unattended interviewing booths that provide attendees the time and space they need to respond to open-ended questions.

While all of the sticky note responses were anonymous, thus not allowing us the ability to track responses as a function of demographics, from our observational impressions, we note that First Friday attendees were more diverse in age and race. With refinement and more detailed data collection, it may be possible for the installation we built to serve as a more robust tool to highlight public perceptions of the social responsibility of engineers as a function of place, demographics, and perhaps even political beliefs. In other words, the installation might elicit responses to our questions that are reflective of the community in which it is installed. In the future we plan on putting up our installation in places that are demographically and politically diverse.

Also, to encourage more back-and-forth and engaged conversation, we could certainly imagine having more people on the team conducting interviews, but perhaps more interestingly, we could also imagine actively grouping sticky notes based on emerging themes during the installation itself and having attendees respond to the emerging themes. It is also possible to expand the technological features of the border wall by adding surveillance technologies like cameras and infrared sensors to it, and having attendees engage in dialogue about the social responsibility of engineers and engineering--not only in building border walls, but also in building the broader suite of technologies used along the US-Mexico border.

\section{Conclusions}

We have designed, built, and exhibited an art installation that uses the case of the US-Mexico border wall to generate public dialogue about the social responsibility of engineers and engineering. The installation is easy to assemble and disassemble, and we have created a design 
and execution packet freely available to anyone who is interested in building their own installation. (If you are interested, please reach out to us.) With proper planning and execution, the installation can be used as a research tool to understand how audiences-from engineering students to those who may not have any experience in engineering-understand the social responsibility of engineers and engineering. The fact that engineering is involved in highly political issues-from climate change caused by fossil fuel extraction to how we understand truth itself because of deepfakes-makes it imperative that we find new ways to highlight the crucial role that engineers and engineering play in shaping society, and new ways to hold engineers and engineering accountable.

\section{Acknowledgements}

We want to thank Cade Lortie and his father Josh, Migle Varkalaite, Aliya Hoff, the ASU Facilities Team, and the ASU School for the Future of Innovation in Society Events Team for their help in designing, building, and executing this project. We would also like to thank Dr. Paula Ioanide for her input on the paper, as well as the editor and reviewer of the paper for their guidance on strengthening the paper.

\section{Author Biography}

Madison Macias is an Arizona native and undergraduate student earning her bachelor's degree in Mechanical Engineering with concentration in energy and environment. She works with local organizations to foster interest in STEM fields among girls in primary school. She enjoys studying the future of sustainable cities, green infrastructure and non-lethal solutions.

\section{Author Biography}

Peter Pohorily is a fourth generation Phoenix native, Peter presently studies at Arizona State University concentrating on Innovation in Society and Sustainability. After completing his undergrad studies, he will go on to earn his masters in Science and Technology Policy. Peter seeks work that dives into the most complex issues of the 21st century. He is interested in how to advance science and technology responsibly to better serve society, through innovative policy. Peter dedicates his time volunteering, and is passionate about engaging with local communities throughout Arizona and the world.

\section{Author Biography}

Jorge Morales Guerrero grew up in the city of Puebla in México where he got his bachelor's degree in Multicultural Relations at the Universidad de las Américas Puebla. He has worked for almost five years in the Sierra Madre Occidental in the state of Chihuahua with and for indigenous 
peoples. He holds a master degree in Social and Cultural Pedagogy from ASU and he is a PhD student in Sustainable Energy in the School of Sustainability at ASU.

\section{Author Biography}

Darshan M.A. Karwat is an unexpected academic, an aerospace engineer by training, with a background in combustion chemistry and sustainability ethics from the University of Michigan. $\mathrm{He}$ is the lead of re-Engineered, an interdisciplinary laboratory focused on embedding environmental protection, justice, and peace in engineering. Before coming to Arizona State University, he, as an AAAS Science and Technology Policy Fellow, worked at the US Environmental Protection Agency on climate change resilience and community-based air pollution monitoring, and then at the US Department of Energy as the Technical Lead of the Wave Energy Prize.

\section{References}

Adely, Hannan, and Monsy Alvarado. 2017. “New Jersey Companies Want to Help Build Trump's Border Wall." North Jersey. March 8, 2017. https: / / www.northjersey.com/story/news / 2017/03/08/new-jersey-companies-wanthelp-build-trumps-border-wall/98911702/.

Adler, Ben. 2017. "Blacklisted For Building Trump's Wall? California Considers It." NPR. https: / / www.npr.org/2017 / 05 / 02/526514203/ states-move-to-blacklist-southernborder-wall-contractors.

Artlink, Inc. 2019. "First Fridays." Artlink Inc. I The Home For Phoenix First Fridays and Art Detour. 2019. https: / / artlinkphx.org / first-fridays/.

Barniskis, Shannon Crawford. 2014. "STEAM: Science and Art Meet in Rural Library Makerspaces," March. https:/ / doi.org/10.9776/14158.

Bender, Michael C. 2019. "How the Border Wall, Trump's Signature Campaign Promise, Turned Into a National Emergency." Wall Street Journal, February 15, 2019, sec. Politics. https: / / www.wsj.com/articles / trump-promised-to-build-that-wall-then-ran-out-oftime-and-options-11550262854.

Berrien, Hank. 2018. “CA Cities Ratchet Up Blacklist Of Businesses Involved In Building Border Wall." The Daily Wire. July 31, 2018. https:/ / www.dailywire.com/ news / ca-cities-ratchetblacklist-businesses-involved-hank-berrien.

Besley, J. 2010. "Current Research on Public Perceptions of Nanotechnology." Emerging Health Threats Journal 3 (September). https: / / doi.org/10.3134/ehtj.10.164.

Born to Engineer. 2017. "Engineers Propose Turning the US Border Wall Into a Hyperloop." Born to Engineer. April 14, 2017. https://www.borntoengineer.com/made-collectivehyperloop-mexico-usa-wall-otra-nation. 
Brinklow, Adam. 2017. “Oakland Won't Do Business with Border Wall Contractors.” Curbed SF. December 1, 2017. https:/ / sf.curbed.com/2017/12/1/16724488/ oakland-bans-contractswith-border-wall-bidders.

Bump, Philip. 2016. "Here's What Donald Trump Said in His Big Immigration Speech, Annotated." Washington Post. August 21，2016. https://www.washingtonpost.com/news/the$\mathrm{fix} / \mathrm{wp} / 2016 / 08 / 31 /$ heres-what-donald-trump-said-in-his-big-immigration-speechannotated $/$.

Clarke, Marie. 2019. "STEM to STEAM: Policy and Practice." In The STEAM Revolution: Transdisciplinary Approaches to Science, Technology, Engineering, Arts, Humanities and Mathematics, edited by Armida de la Garza and Charles Travis, 223-36. Cham: Springer International Publishing. https:/ / doi.org/10.1007/978-3-319-89818-6_15.

Crabtree, Susan. 2018. "Dems Expand Push to Blacklist Businesses Working on Trump's Border Wall." Washington Free Beacon. July 31, 2018. https://freebeacon.com/issues/demsexpand-push-blacklist-businesses-working-trumps-border-wall/.

Doubek, James. 2017. "Customs And Border Protection Outlines Border Wall Requirements." The Two-Way: NPR. 2017. https://www.npr.org/sections/thetwoway / 2017/03/18/520626117/ customs-and-border-protection-outlines-border-wallrequirements.

engineerscanada. 2017. "Public Perceptions of Engineers \& Engineering." Innovative Research Group. https:/ / engineerscanada.ca/ reports / public-perceptions.

Fast, Ethan, and Eric Horvitz. 2017. "Long-Term Trends in the Public Perception of Artificial Intelligence." In Thirty-First AAAI Conference on Artificial Intelligence. https: / / www.aaai.org/ocs/index.php/AAAI/AAAI17/ paper/view/14581.

Felt, Ulrike, Rayvon Fouché, Clark Miller, and Laurel Smith-Doerr. 2017. The Handbook of Science and Technology Studies, Fourth Edition.

G., Al. 2018. "State and Cities Blacklisting Border Wall Contractors." ACG The Construction Association. April 5, 2018. https: / / advocacy.agc.org/state-and-cities-blacklisting-borderwall-contractors.

Guerrero, Jean. 2017. “San Diego Companies Wait To Bid On Trump's Border Wall." KPBS Public Media. March 8, 2017. https://www.kpbs.org/news/2017/mar/08/san-diegocompanies-wait-bid-trumps-border-wall/.

Guyotte, Kelly W., Nicki W. Sochacka, Tracie E. Costantino, Joachim Walther, and Nadia N. Kellam. 2014. "Steam as Social Practice: Cultivating Creativity in Transdisciplinary Spaces." Art Education 67 (6): 12-19. https: / / doi.org/10.1080/00043125.2014.11519293.

Hecht, Gabrielle, and Michel Callon. 2009. The Radiance of France: Nuclear Power and National Identity after World War II. Cambridge, Mass.: MIT Press.

Hedding, Judy. 2019. "15 Things to Know About First Friday in Phoenix." TripSavvy. January 11, 2019. https: / / www.tripsavvy.com/ first-friday-in-phoenix-2677403.

Ioanide, Paula. 2015. The Emotional Politics of Racism: How Feelings Trump Facts in an Era of Colorblindness. Stanford: Stanford University Press.

http:/ / www.sup.org/books/ title / ?id=25108. 
IPCC. 2015. “Climate Change 2014: Synthesis Report." Geneva, Switzerland: Intergovernmental Panel on Climate Change.

Johnson, Jenna. 2016. "'Build That Wall' Has Taken on a Life of Its Own at Donald Trump's Rallies - but He's Still Serious." Washington Post. February 12, 2016. https: / / www.washingtonpost.com/news / post-politics/wp/2016/02/12/ build-thatwall-has-taken-on-a-life-of-its-own-at-donald-trumps-rallies-but-hes-still-serious/ .

Kaplan, Leah, John Nelson, David Tomblin, Mahmud Farooque, Jason Lloyd, Mark Neff, Bjørn Bedsted, and Dan Sarewitz. 2019. "Cooling a Warming Planet? Public Forums on Climate Intervention Research.” https://cspo.org/research/governance-of-geoengineeringresearch/project-report/.

Karwat, Darshan M. A. 2018. "When Mental Walls Lead to Physical Walls: First Showing." ReEngineered: Blog (blog). April 23, 2018. https://reengineered.blog/2018/04/23/whenmental-walls-lead-to-physical-walls-first-showing/.

—_ 2019. "Self-Reflection for Activist Engineering." Science and Engineering Ethics, October. https: / / doi.org/10.1007/ s11948-019-00150-y.

Koscak, Paul. 2017. "Construction Completed for Prototype Wall Designs." U.S. Customs and Border Protection. March 18, 2017. https://www.cbp.gov/frontline/border-wallprototype-designs.

Kullman, Joe. 2019. "Turning Borderlands into an Energy-Water Innovation Zone." ASU Now: Access, Excellence, Impact. May 13, 2019. https:/ / asunow.asu.edu/20190513-solutionsturning-borderlands-energy-water-innovation-zone.

Macias, Madison. 2019. "Re-Engineered I Work." Reengineered. December 2019. https: / / www.reengineered.org/work.

Marshall, Helen, Lynne McClymont, and Lucy Joyce. 2007. "Public Attitudes to and Perceptions of Engineering and Engineers 2007." United Kingdom: The Royal Academy of Engineering. https: / / www.raeng.org.uk/ publications / other/public-attitude-perceptionsengineering-engineers.

Miller, T. Christian. 2017. "Trump Invites Bids to Build Wall, Cites Importance of 'Aesthetics.'” Text/html. ProPublica. March 8, 2017. https://www.propublica.org/article/trumpinvites-bids-to-build-wall-cites-importance-of-aesthetics.

Miroff, Nick. 2019. "Smugglers Are Sawing through New Sections of Trump's Border Wall." $\begin{array}{llll}\text { Washington Post. } & \text { November } & 2019 .\end{array}$ https: / / www.washingtonpost.com/national/smugglers-are-sawing-through-newsections-of-trumps-border-wall/2019/11/01/25bf8ce0-fa72-11e9-ac8c8eced29ca6ef_story.html.

Noble, David F. 1978. "America by Design: Science, Technology, and the Rise of Corporate Capitalism." Newsletter on Science, Technology \& Human Values 3 (1): 61-61. https: / / doi.org/10.1177/016224397800300158.

Orenstein, Natalie. 2017. "Berkeley Becomes First City to 'divest' from Trump's Border Wall." Berkeleyside. March 17, 2017. https://www.berkeleyside.com/2017/03/17/berkeleybecomes-first-city-divest-trumps-border-wall. 
Otto, Amy. 2018. "Personal Correspondence with Darshan Karwat."

Rizzo, Salvador. 2019. “More than Two Years Later, Trump's Wall Remains Unbuilt.” Washington Post. September 6, 2019. https: / / www.washingtonpost.com/ politics/2019/09/06/morethan-two-years-later-trumps-wall-remains-unbuilt/.

Rodgers, Lucy, and Dominic Bailey. 2019. "Trump's Border Wall - in Seven Charts." BBC News. September 27, 2019. https:/ / www.bbc.com/news/world-us-canada-46824649.

Scott, Eugene. 2015. "Trump Talks Immigration, Marriage and ISIS." CNN. June 28, 2015. https: / / www.cnn.com/2015/06/28/ politics / donald-trump-immigration-gay-marriage2016/index.html.

—_. 2019. "Analysis I Trump's Most Insulting - and Violent - Language Is Often Reserved for Immigrants." Washington Post. October 2, 2019. https: / / www.washingtonpost.com/ politics / 2019/10/02/trumps-most-insultingviolent-language-is-often-reserved-immigrants /.

SFIS ASU. 2018. Future of X: Border Wall. Future of X. Phoenix, Arizona. https: / / www.youtube.com/ watch?v=ia6bL7mQWyY\&list=PL2QzSvx3vOykTm_D7g5jX V14mWzf255gY\&index $=2$.

Villasenor, John. 2019. "Artificial Intelligence, Deepfakes, and the Uncertain Future of Truth." Brookings (blog). $\quad$ February 2019. https: / / www.brookings.edu/blog/techtank/2019/02/14/artificial-intelligencedeepfakes-and-the-uncertain-future-of-truth/.

Wong, Julia Carrie. 2017. “One in 10 Firms Bidding for Trump's Mexico Wall Project Are HispanicOwned." The Guardian. March 11, 2017. https://www.theguardian.com/usnews / 2017/mar/11/mexico-border-wall-hispanic-owned-construction-companies. 